\title{
PAPERS
}

\section{Eradication of Barrett's mucosa with argon plasma coagulation and acid suppression: immediate and mid term results}

\author{
J-L Van Laethem, M Cremer, M O Peny, M Delhaye, J Devière
}

\begin{abstract}
Background-Intestinal metaplastic mucosa in Barrett's oesophagus can be replaced by squamous epithelium after mucosal thermal ablation associated with acid suppression therapy.

Aims-To assess whether restoration of squamous epithelium can be obtained after ablation of Barrett's oesophagus using argon plasma coagulation (APC) associated with proton pump inhibitor (PPI) therapy.
\end{abstract}

Methods-Thirty one patients with Barrett's oesophagus received APC. Omeprazole (40 mg/day) was given from the first APC application to one month after completion of the treatment, then given symptomatically. Twenty four hour pH-metry was performed during endotherapy.

Results-Complete re-epithelialisation was visualised at endoscopy in 25/31 patients $(81 \%)$ after a mean number of 2.4 APC sessions (range 1-4). Only partial squamous re-epithelialisation was observed in three patients and three others had no eradication. At histological assessment, eradication of Barrett's oesophagus was only confirmed in $19 / 31$ patients $(61 \%)$ due to the presence of a few residual Barrett's glands under the new squamous epithelium. Complete eradication was related to a Barrett's oesophagus segment length of less than $4 \mathrm{~cm}$ and the absence of circumferential extension but not to the normalisation of oesophageal acid exposure under PPI therapy. Seventeen patients with apparently complete endoscopic and histological eradication of Barrett's oesophagus were re-evaluated at one year; eight $(47 \%)$ disclosed relapsing islands of Barrett metaplasia despite continuous omeprazole therapy (10-40 mg/day).

Conclusions-APC combined with $40 \mathrm{mg}$ omeprazole daily can eradicate Barrett's mucosa with apparent squamous reepithelialisation in the majority of patients even in the absence of normalisation of oesophageal acid exposure. However, one year after endotherapy for Barrett's oesophagus, relapse is frequent but limited in extent.

(Gut 1998;43:747-751)
Keywords: Barrett's oesophagus; argon plasma coagulation; omeprazole; gastro-oesophageal reflux; Barrett's adenocarcinoma

Barrett's oesophagus is considered to be a premalignant lesion and is found in $10-20 \%$ of patients undergoing upper gastrointestinal (GI) endoscopy for symptoms of gastrooesophageal reflux disease (GORD). ${ }^{12}$ The normal squamous epithelium is replaced by a specialised columnar epithelium (SCE) referred to as intestinal metaplasia. Intestinal metaplasia can evolve into adenocarcinoma in a well defined metaplasia-dysplasia-carcinoma sequence. ${ }^{3}$ The incidence of adenocarcinoma in Barrett's oesophagus is reported as being highly variable, ranging from $1 / 52$ to $1 / 441$ cases per patient year with a relative risk 30 to 125 times greater among patients with Barrett's oesophagus than in the general population. ${ }^{24}$ Interestingly, the incidence of adenocarcinoma of the oesophagus and the cardia has rapidly risen in Western countries over the past 20 years. ${ }^{5}$

As it is a premalignant condition, it is commonly recommended that patients with Barrett's oesophagus be followed periodically in order to detect high grade dysplasia or cancer at an earlier and potentially curable stage. However, it is not clear whether surveillance can influence survival and whether it is effective on the basis of cost benefit analyses. ${ }^{6}$ Attempts to reverse Barrett's oesophagus in order to prevent the development of adenocarcinoma and obviate the need for further surveillance may therefore be an attractive strategy.

The use of medical therapy with high dose omeprazole and antireflux surgery in reversing Barrett's oesophagus remains controversial and disappointing with regression observed only after long term maintenance with high doses (40 to $80 \mathrm{mg} /$ day) of omeprazole. ${ }^{7-9}$ However, these studies showed that squamous dedifferentiation can be achieved in metaplastic intestinal metaplasia during proton pump inhibitor therapy. Squamous epithelium reappears as confluent islands in Barrett's oesophagus. Furthermore, there is recent experimental evidence suggesting a multipotential cell as the cell of origin of Barrett's epithelium. ${ }^{10}$

Recently, the use of laser therapy (NdYAG, photodynamic therapy, argon laser) or 
Figure 1 Circumferential Barrett's mucosa before endotherapy.

Figure 2 Barrett's mucosa at

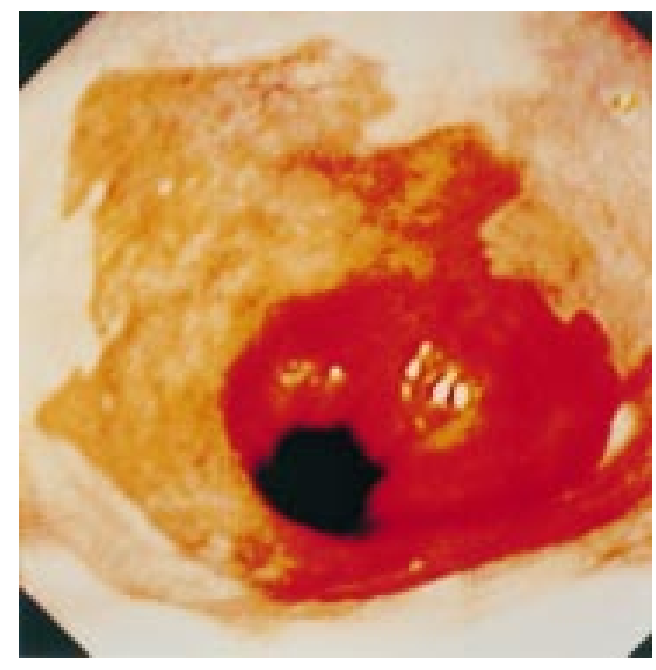

multipolar electrocoagulation combined with acid suppression has been shown to be effective for ablating Barrett's columnar epithelium. All these methods showed that injury to the metaplastic epithelium in an acid suppressed environment often results in squamous reepithelialisation of the targeted sections and partial regression of Barrett's segments. ${ }^{11-15}$

Argon plasma coagulation (APC) is a new non-contact electrocoagulation procedure used in flexible endoscopy. High frequency energy is transmitted to tissue by an ionised gas (argon plasma) and is suitable for thermal coagulation of tissue surfaces of $2-3 \mathrm{~mm}$, permitting the devitalisation of defined pathological tissue layers. ${ }^{16}{ }^{17}$

The aim of this prospective controlled study was twofold. Firstly, we attempted to assess whether complete restoration of squamous epithelium can be achieved in patients with Barrett's oesophagus using the APC application combined with omeprazole $40 \mathrm{mg} /$ day. Secondly, we evaluated whether profound acid inhibition should be maintained in the case of successful squamous re-epithelialisation. We report our early and mid term data focusing on the feasibility and efficiency of this novel method for complete eradication of Barrett's mucosa.

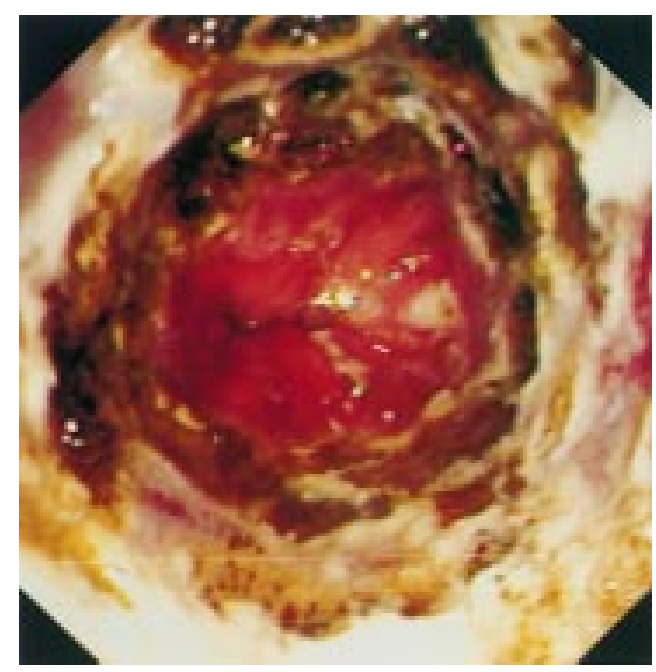

\section{Materials and methods}

PATIENTS

The study was approved by our Institutional Review Board and informed consent was obtained from each patient treated.

In total 31 patients ( 25 men, six women; mean (SD) age 64 (8) years, range 46-76) undergoing upper GI endoscopy for suspected GORD or already followed for well characterised Barrett's oesophagus and treated with omeprazole 20 $\mathrm{mg} /$ day, were enrolled. Inclusion criteria included the presence of Barrett's oesophagus of at least $3 \mathrm{~cm}$ in length with biopsy proved specialised columnar epithelium.

Patients with the following criteria were excluded: intolerance to upper GI endoscopy, life expectancy under five years, intercurrent disease precluding the vital prognosis, previous history of gastro-oesophageal surgery (Nissen fundoplication, gastrectomy, Heller or Whipple procedure), use of non-steroidal anti-inflammatory drugs, and Barrett's oesophagus with high grade dysplasia or carcinoma.

\section{STUDY AND TREATMENT PROCEDURES}

All patients underwent a baseline diagnostic endoscopy to measure the extent of the Barrett's oesophaegus accurately. The lesions were defined as being either circumferential or composed of tongues and islands. The length of the Barrett's segment was determined by measuring the distance between the most proximal point of columnar mucosa to the ex $\mathrm{Z}$ line as referenced to the distance from the incisors (in $\mathrm{cm}$ ). The ex $\mathrm{Z}$ line was located as the vascular border at the end of the tubular oesophagus or at the proximal margin of hiatal hernia folds. Chromoendoscopy using toluidine blue staining after washing the mucosa with $1 \%$ acetic acid was also performed in order to define better the Barrett's margins. ${ }^{18}$ All measurements were performed when pulling out the endoscope. All procedures were videotaped for reassessment by a second endoscopist.

Multiple biopsy specimens were obtained in four quadrants at $2 \mathrm{~cm}$ intervals throughout the Barrett's oesophagus as previously recommended ${ }^{19}$ and reviewed by one or two (in the case of dysplasia) experienced pathologists. Biopsies were performed at the baseline endoscopy, after completion of Barrett's endotherapy, and during follow up.

\section{BARRETT'S ENDOTHERAPY}

The APC equipment consists of an argon gas source (Argon Beamer Two, ERBE Elektromedizin, Tübingen, Germany) and a high frequency surgical unit which delivers a monopolar electric current (Erbotom ICC 350 , ERBE). APC is applied to the oesophageal mucosa using an argon plasma coagulation probe, a flexible Teflon tube which is introduced and operated through the working channel of the gastroscope (GIF-2T-130, Olympus, Hamburg, Germany). APC is delivered until a white coagulum develops either circumferentially, point by point for a short segment, or by achieving longitudinal strips in a backward direction during withdrawal of the scope (figs 1 and 2). 
Figure 3 Biopsy specimen sampled in an area of squamous appearing mucosa but showing persistence of a few remaining metaplastic glands under the new squamous epithelium.

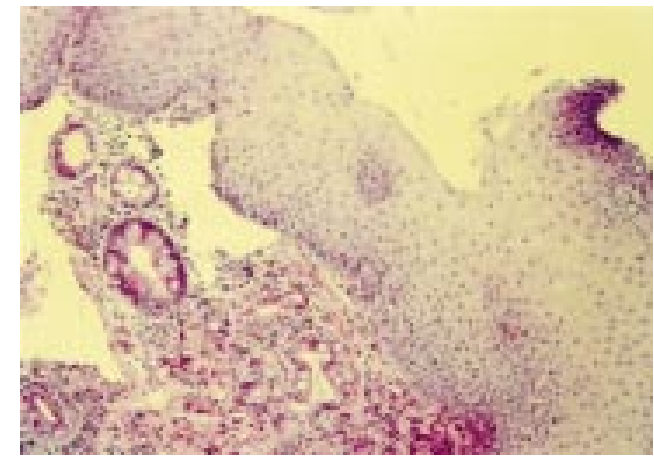

The procedures were performed under intravenous premedication with midazolam, pethidine, and glucagon and were well tolerated. Cardiac monitoring and pulse oxymetry were used on a routine basis; total treatment duration was approximatively 15 to 20 minutes per session. APC was reapplied every month until complete squamous re-epithelialisation of the specialised columnar segment (SCE) was observed - that is, when the new pearly white squamous appearing mucosa has reached the ex $\mathrm{Z}$ line, with a maximal number of four sessions. One month after the last APC treatment, apparent re-epithelialisation of the entire oesophagus was confirmed by sampling four quadrants by biopsy every $2 \mathrm{~cm}$ throughout the previous Barrett's segment after endoscopy assessment and videotaping. Results are respectively provided in terms of chromoendoscopic appearance and of histological confirmation of SCE eradication as follows: apparent complete re-epithelialisation $=$ no finding of SCE within the squamous appearing epithelium; partial re-epithelialisation $=$ finding of residual SCE islands, tongues, or segments above the ex $\mathrm{Z}$ line, expressed as the percentage of ablated Barrett's mucosa compared with the initial Barrett's length (percentage); or failure in the absence of re-epithelialisation.

During the period of endotherapy, all patients received omeprazole at the daily dose of $40 \mathrm{mg}$. One month after the last treatment, regression of Barrett's mucosa was evaluated and patients with complete re-epithelialisation were randomly assigned to receive either high dose (40 mg/day) or low dose omeprazole (10 $\mathrm{mg}$ /day) in order to evaluate the need for long term maintenance of acid suppression therapy. Follow up endoscopic examinations were performed three months after randomisation, then every six months.

Table 1 Effectiveness of APC in relation to the extent of Barrett's mucosa

\begin{tabular}{llllll}
\hline & \multicolumn{2}{l}{$\begin{array}{l}\text { Length of Barrett's } \\
\text { oesophagus }\end{array}$} & & \multicolumn{2}{l}{$\begin{array}{l}\text { Circumferential Barrett's } \\
\text { oesophagus }\end{array}$} \\
\cline { 2 - 3 } \cline { 5 - 6 } & $\leqslant 4 \mathrm{~cm}$ & $>4 \mathrm{~cm}$ & & Yes & No \\
\hline $\begin{array}{c}\text { Mean (SD) number of APC } \\
\text { sessions }\end{array}$ & $2.05(0.8)$ & $3.2(0.6) \dagger$ & & $2.7(0.8) \ddagger$ & $2(0.9)$ \\
$\begin{array}{c}\text { Number (\%) of complete } \\
\text { re-epithelialisations }{ }^{\star} \text { observed }\end{array}$ & $14 / 18(77 \%) \$$ & $5 / 13(38 \%)$ & & $11 / 21(52 \%)$ & $8 / 10(80 \%)$ \\
\hline
\end{tabular}

${ }^{\star}$ Complete absence of intestinal metaplastic glands $(n=19)$.

$\mathrm{tp}=0.003$ (Mann-Whitney U test); $\neq \mathrm{p}=0.03$ (Mann-Whitney U test); $\mathrm{S}=0.03$ (Fisher's exact test); $\uparrow \mathrm{p}=0.08$ (Fisher's exact test).
TWENTY FOUR HOUR OESOPHAGEAL $\mathrm{pH}$ MONITORING

In order to evaluate whether acid reflux was normalised during the treatment, a 24 hour oesophageal pH-metry was performed in $20 / 31$ patients $(65 \%)$ taking omeprazole $40 \mathrm{mg} /$ day during or after the period of Barrett's oesophagus endotherapy but at least 15 days after the last APC sessions. Results of $\mathrm{pH}$-metry were expressed as a percentage of time of oesophageal acid exposure at a $\mathrm{pH}$ less than 4 . Values above $4.2 \%$ of the time were considered abnormal (absence of normalisation of oesophageal acid exposure). ${ }^{20}$

STATISTICS

The Mann-Whitney U test and Fisher's exact test were applied when appropriate. Significance was assumed when $\mathrm{p}$ was less than 0.05 .

\section{Results}

IMMEDIATE EFFECTIVENESS OF BARRETT'S OESOPHAGUS ENDOTHERAPY

The initial mean length of the Barrett's segment was $4.5(1.7) \mathrm{cm}$ (range $3-11 \mathrm{~cm}$ ). It was circumferential in $21 / 31(67 \%)$ patients and associated with a hiatal hernia in $27 / 31$ patients. Intestinal metaplasia without dysplasia was found in 26/31 patients and with low grade dysplasia in five $(16 \%)$. Patients underwent a mean of 2.4 (0.9) APC applications (range 1-4) within a period ranging from one to four months.

The effectiveness of treatment was evaluated one month after the last application of APC. Endoscopically apparent complete eradication of Barrett's oesophagus was obtained in 25/31 patients $(80.7 \%)$, while partial eradication was observed in three $(9.7 \%)$, consisting of $80 \%$ of the initial Barrett's segment; failure occurred in the other three patients (9.7\%). Among these three patients, one had severe diffuse oesophagitis without re-epithelialisation; an oesophageal stenosis occurred in the other two after the first APC application, requiring endoscopic dilatation; endoscopic treatment of Barrett's metaplasia was then discontinued.

Complete SCE eradication was histologically confirmed in only $19 / 25$ patients with endoscopically apparent complete re-epithelialisation ( $61 \%$ of patients treated) as occasional residual glands of intestinal metaplasia (three to five) were found under the new squamous epithelium in six patients (fig 3). These glands were always localised in the distal part of the treated segment just above the new squamocolumnar junction. Histological findings disclosed the persistence of large areas of intestinal metaplasia in patients with partial re-epithelialisation or stricture.

Table 1 illustrates that the number of APC sessions required for obtaining at least partial re-epithelialisation depends on the Barrett's segment length $(p=0.003)$ and on the presence of circumferential extension $(p=0.03)$. Complete re-epithelialisation was significantly more frequent in short Barrett's segments $(p=0.03)$ or in non-circumferential extents $(\mathrm{p}=0.08$, marginally significant). 
Table 2 Follow up assessment after endotherapy for Barrett's oesophagus

\begin{tabular}{lll}
\hline & No Barrett's mucosa at endoscopy & No specialised columnar epithelium at histology \\
\hline 1 month & $25 / 31(81 \%)$ & $19 / 31(61 \%)$ \\
3 months & $22 / 31(71 \%)$ & $15 / 31(48 \%)$ \\
12 months & $12 / 17^{\star}(70 \%)$ & $9 / 17^{\star}(53 \%)$ \\
\hline
\end{tabular}

${ }^{\star}$ One year assessment was completed in 17 patients.

Most of the patients experienced mild odynophagia or dysphagia for a few days immediately after the first APC application. However, two patients presented with persistent retrosternal pain and odynophagia or dysphagia for a period of three weeks. Three other complications related to the first procedure included an oesophageal stricture in two patients, requiring, respectively, two and three balloon and bougie dilatations, and oesophageal bleeding requiring blood transfusion in one patient, occurring one week after the APC session and probably due to detachment of a clot from a deeply coagulated area.

The 24 hour oesophageal pH monitoring performed in 20 patients showed that only seven patients (35\%) among the 20 investigated had normalisation of oesophageal acid exposure; Barrett's mucosa was completely eradicated in five $(71.4 \%)$ of these patients. Nine of 13 complete eradications $(69.2 \%)$ were observed in the group of patients with persistent acid reflux (not significantly different). One complete failure was observed in the group with persistent acid exposure and one complication (stricture) was observed in each group.

THREE MONTH AND ONE YEAR FOLLOW UP POST BARRETT'S ENDOTHERAPY

The patients were reassessed three months after confirmation of complete eradication of Barrett's mucosa. Maintenance of squamous appearing mucosa was endoscopically observed in $22 / 31(71 \%)$ patients, three patients showing endoscopic reappearance of SCE ( $20 \%$ of the initially treated segment); in four others, a few areas of intestinal metaplasia without endoscopic features of Barrett's oesophagus were observed. Two patients of the three with partial re-epithelialisation progressed, with recurrence of SCE in $40 \%$ of the initially treated area (table 2).

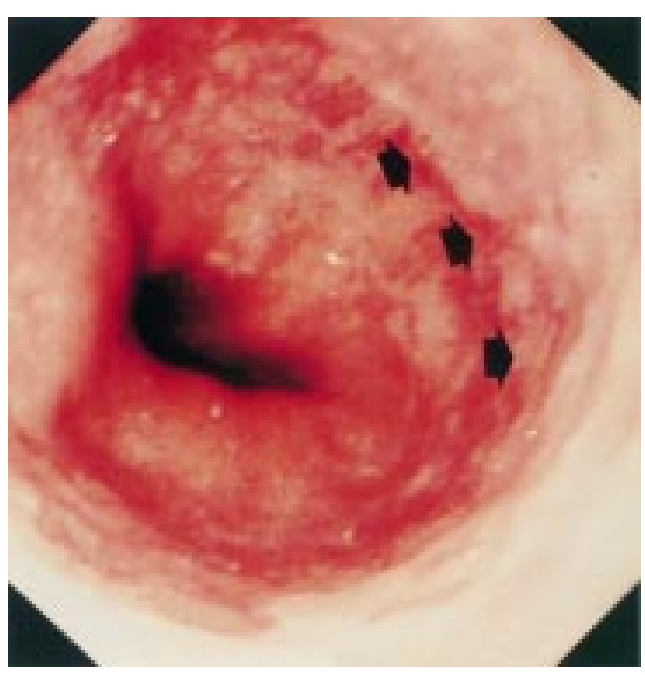

Figure 4 Barrett's mucosa one year after complete persistence of squamous Arrowheads represent new squamocolumnar junction. re-epithelialisation showing
The two patients with oesophageal strictures were successfully managed with dilatation and no residual stenosis was observed three months after the last dilatation session.

Eight patients had symptoms and endoscopic appearances of reflux oesophagitis during early follow up. Most (six) had discontinued the high dose of omeprazole and were taking $10 \mathrm{mg} /$ day.

So far, 17 patients with apparently complete histological eradication of Barrett's mucosa have been assessed one year after endotherapy. Complete re-epithelialisation appeared to be endoscopically maintained in 12 patients (fig 4 ) but only nine $(53 \%)$ were found to be totally cleared of metaplastic glands (table 2). In the other five patients, recurrent specialised columnar epithelium was seen, occupying 10 to $50 \%$ of the initially treated area. Among the nine patients with complete histological eradication, five took 10 $\mathrm{mg}$ omeprazole and four took $40 \mathrm{mg}$ daily.

\section{Discussion}

The management of Barrett's oesophagus remains a challenging problem and this is mainly due to a lack of knowledge of its natural history. Ablation of Barrett's epithelium combined with profound acid inhibition thus represents a new attractive therapy in this setting, although only preliminary data are available.

An attempt to obtain restoration of squamous epithelium is of major importance to validate this new approach as it is only the total absence of specialised columnar epithelium that has the potential to remove the risk of cancer development. Furthermore, a completely reepithelialised oesophagus probably represents the best model for the long term study of the natural history of Barrett's oesophagus. The feasibility of complete eradication of Barrett's oesophagus using APC associated with omeprazole treatment has been confirmed with an immediate success rate of $81 \%$ when the endoscopic appearance is considered and $61 \%$ when strict histological criteria are applied for the complete elimination of all Barrett's mucosa. Indeed, persistence of occasional (one to five) residual metaplastic glands under the new layer of squamous epithelium (most often in the distal part of the former SCE) was observed in 6/25 patients with complete visual eradication of Barrett's oesophagus and was also reported by other investigators using argon laser, PDT, or multipolar electrocoagulation for ablating SCE. ${ }^{11-15}$ The relevance of these residual glands in the outcome of re-epithelialised mucosa remains to be determined. These small areas are localised only distally at the junction between squamous and columnar mucosa and are observed even after using PDT which is thought to ablate dysplastic cells selectively. ${ }^{21}$ In our study design, we chose not to apply further APC treatment in these cases and to follow the patients. At our intermediate follow up evaluation, these remaining glands persisted but did not seem to have lead to extensive recurrence of specialised columnar epithelium.

The effectiveness of Barrett's oesophagus

re-epithelialisation is related to the extent of 
metaplasia and a higher rate of complete ablation was observed in the shorter and uncircumferential Barrett's oesophagus. However, the success of the procedure does not seem to depend on the complete normalisation of oesophageal acid exposure. Indeed, we observed that only one third of the treated patients have no more acid reflux under omeprazole 40 $\mathrm{mg}$ /day and interestingly, there was no difference between patients with persistent reflux and those without acid reflux in terms of the complete re-epithelialisation rate or complications, as recently reported. ${ }^{22}$ Nevertheless, it is probable that an optimal control of acid reflux is necessary to obtain long term maintenance of squamous re-epithelialisation.

The next question is therefore whether the squamous re-epithelialisation can be maintained in the long term. This was observed here in only $9 / 17$ patients $(53 \%)$ after one year. One of the critical points of interest is to determine whether high doses of proton pump inhibitors are necessary to maintain complete reepithelialisation of Barrett's oesophagus and at what level of acid exposure might reappearance of specialised columnar epithelium be expected. We have not answered these questions in this preliminary one year follow up study which included only 17 of our 31 patients. However, we observed relapse of SCE in both groups, treated with omeprazole 10 or $40 \mathrm{mg}$ daily, suggesting that either long term acid suppression does not play a role, or higher doses ( $80 \mathrm{mg}$ daily) may be required as previously suggested. ${ }^{114}$ The purpose of the follow up study we have started is to evaluate whether high doses of the PPI (acceptable from an economic point of view) are necessary to maintain regression. The two or three years' follow up of the patients with complete re-epithelialisation who randomly receive 10 or $40 \mathrm{mg}$ of omeprazole would probably determine which dose of maintenance therapy is mandatory for each individual patient for the optimal control of reflux. Interestingly, in young and fit patients, antireflux surgery would be probably the best strategy after successful squamous re-epithelialisation.

The procedures were performed on an outpatient basis and were generally well tolerated. Advantages of APC included its easy mobility and low cost. Some technical improvement could however contribute to better and safer application: the area of coagulation could be enlarged and the direction of the argon flow could be laterally observed, facilitating application in the oesophagus. However, although the procedures were performed by experienced endoscopists, three procedure related complications occurred despite a theoretical limited penetration depth of $2-3 \mathrm{~mm}$. A similar rate of complication was observed with multipolar electrocoagulation. ${ }^{14}$ Occurrence of strictures is probably related to deep coagulation which affects the muscularis propia; it is, however, difficult to predict these and we were not able to identify a technical problem which may have been responsible for their occurrence. This is one reason why this treatment remains experimental.
In summary, complete eradication of Barrett's oesophagus is feasible using APC but endoscopic regression is overestimated when compared with proved histological regression. However, the relevance of persistent occasional metaplastic glands under the new squamous epithelium remains undetermined. One year after endotherapy, relapse or progression may occur despite maintenance omeprazole therapy. This procedure is not totally devoid of risk and complications may occur. Therefore, it is clearly not recommended to treat patients on a routine basis but only within prospective trials assessing the natural history of reepithelialised Barrett's oesophagus. Notably Nissen fundoplication following complete eradication of SCE could be an attractive strategy in the future management of Barrett's oesophagus arising in young patients.

The authors acknowledge J-M Dumonceau, A Van Gossum, N Bourgeois, $M$ Adler, and A Vandermeeren for participating in this study. The authors also thank Mrs D Delannoy for her helpful assistance and F Martinez Vadillo for typing the manuscript. This work was supported by a research grant from Astra Belgium.

1 Spechler SJ, Goyal RK. Barrett's oesophagus. N Engl f Med 1986;315:362-71.

2 Falk GW, Richter JE. Reflux disease and Barrett's oesophagus. Endoscopy 1996;28:13-21.

3 McArdle JE, Lewrin KJ, Randall G, et al. Distribution of dysplasias and early invasive carcinoma in Barrett's oesophagus. Hum Pathol 1992;23:479-82.

4 Spechler SJ, Robbins AH, Rubins HB, et al. Adenocarcinoma and Barrett's oesophagus: an overrated risk? Gastroenterology 1984;87:927-33.

5 Pera M, Cameron AJ, Trastek VF, et al. Increasing incidence Pera $\mathrm{M}$, Cameron $\mathrm{AJ}$, Trastek $\mathrm{VF}$, et al. Increasing incidence
of adenocarcinoma of the oesophagus and esophagogastric junction. Gastroenterology 1993;104:510-13.

6 Spechler SJ. Endoscopic surveillance for patients with Barrett's oesophagus: does the cancer risk justify the practice? Ann Intern Med 1987;106:902-4.

7 Gore S, Healey CJ, Sutton R. Regression of columnar-lined (Barrett's) oesophagus with continuous omeprazole therapy. Aliment Pharmacol Ther 1993;7:623-8.

8 Devière J, Buset $M$, Dumonceau JM, et al. Regression of Barrett's epithelium with omeprazole [letter]. N Engl F Med 1989;320:1497-8.

9 Malesci A, Savarino V, Zentilin P, et al. Partial regression of Barrett's oesophagus by long-term therapy with high-dose omeprazole. Gastrointest Endosc 1996;44:700-57.

10 Boch JA, Shields HP, Antonioli DA, et al. Distribution of cytokeratin markers in Barrett's specialized columnar cytokeratin markers in Barrett's specialized

11 Berenson MM, Johnson TD, Markowitz NR, et al. RestoraBerenson MM, Johnson TD, Markowitz NR, et al. Restora-
tion of squamous mucosa after ablation of Barrett's esophation of squamous mucosa after ablation of Barrett's

geal epithelium. Gastroenterology 1993;104:1686-91.
2 Brandt LJ, Kanvar DR. Laser-induced transient regression of Barrett's epithelium. Gastrointest Endosc 1993;38:619-22.

13 Laukka MA, Wang KA. Initial results using low dose photodynamic therapy in the treatment of Barrett's oesophagus. Gastrointest Endosc 1995;42:59-63.

14 Sampliner RE, Femerty B, Garewal HS. Reversal of Barrett's oesophagus with acid suppression and multipolar electrocoagulation: preliminary results. Gastrointest Endosc 1996;44:523-5.

15 Barham CP, Jones RL, Biddlestone LR, et al. Photothermal laser ablation of Barrett's oesophagus: endoscopic and histological evidence of squamous re-epithelialisation. Gut 1997;41:281-4

16 Wahab PJ, Mulder CJJ, den Hartog G, et al. Argon plasma coagulation in flexible gastrointestinal endoscopy: pilot experiences. Endoscopy 1997;29:176-87.

17 Grund KE, Storek D, Farin G. Endoscopic argon plasma coagulation (APC): first clinical experiences in flexible coagulation (APC): first clinical experien

18 Chobanian SJ, Catton EL, Winters C, et al. In vivo staining with toluidine blue as an adjunct to the endoscopic detection of Barrett's oesphagus. Gastrointest Endosc 1987;33:99-101.

19 Levine DS, Reid BJ. Endoscopic biopsy technique for acquiring larger mucosal samples. Gastrointest Endosc 1991; 37:332-7

20 Johnson LF, De Meester TR. Twenty-four hour $\mathrm{pH}$ monitoring of the distal oesophagus. Am f Gastroenterol 1974;62:325-32.

21 Overholt BF, Panjehpour M. Barrett's oesophagus: photodynamic therapy for ablation of dysplasia, reduction of specialized mucosa and treatment of superficial esophageal cancer. Gastrointest Endosc 1995;42:64-9.

22 Kovacs BJ, Chen YK, Lewis TD, et al. Reversal of Barrett's oesophagus with multipolar electrocoagulation: is acid 45:A191.
45:ension important [abstract]? Gastrointest Endosc 1997; 